CONGENITAL HEART DISEASE

\title{
Parents' understanding of their child's congenital heart disease
}

\author{
D K L Cheuk, S M Y Wong, Y P Choi, A K T Chau, Y F Cheung
}

Heart 2004;90:435-439. doi: 10.1136/hrt.2003.014092

See end of article for authors' affiliations

Correspondence to:

Dr Y F Cheung, Division of Paediatric Cardiology, Department of Paediatrics and Adolescent Medicine, Grantham Hospital, The University of Hong Kong, 125 Wong Chuk Hang Road, Hong Kong, China; xfcheung@hkucc.hku.hk

Accepted 31 July 2003
Objectives: To assess parents' understanding of their child's congenital heart disease in various knowledge domains and to identify significant determinants of parental knowledge.

Design: Cross sectional questionnaire survey

Setting: Tertiary paediatric cardiac centre.

Patients: 156 parents of children with relatively simple congenital heart defects were recruited from the outpatient clinic of a tertiary cardiac centre over a three month period. The questionnaire comprised 10 items of knowledge under three domains: nature of heart disease and its treatment; impact of heart disease on exercise capacity; and infective endocarditis and its prevention. The frequency distribution of the parents' knowledge in the different domains was determined. Univariate analyses and logistic regression were performed to identify significant determinants of knowledge in selected items.

Results: While $59 \%$ of parents correctly named their child's congenital heart disease, only $28.8 \%$ correctly indicated the heart lesion(s) diagrammatically. However, more than $80 \%$ of parents were aware of the indications and aims of previous surgical and transcatheter interventions. About half of the parents were aware of possible aetiologies and of the hereditary nature and symptoms attributable to underlying heart disease. Disappointingly, of the 56 parents whose children were taking cardiac medications, only 25 $(44.6 \%)$ and $4(7.1 \%)$ knew correctly the functions and important side effects of the medications, respectively. With regard to exercise capacity, 59\% of parents indicated its level appropriate for the heart lesion. While $26.9 \%$ of parents had heard of the term "infective endocarditis", slightly more than half of the parents were aware of the need for antibiotics before dental procedures. Significant determinants of knowledge in the nature of heart disease were cardiac diagnosis, occupation of parents, and their educational level. Logistic regression failed to identify any significant determinants of parental knowledge in the other two domains.

Conclusions: Parents of children with congenital heart disease have important knowledge gaps. Our findings suggest that the current educational programme is inadequate and needs to be refined to promote better parental understanding of their child's heart disease, with the ultimate aim of enabling parents to impart such knowledge accurately to their children.
T he knowledge of one's own disease is an important determinant of health related behaviour. ${ }^{1}$ Much effort has therefore been devoted to educating patients with chronic diseases in an attempt to change their health behaviour and maximise their health benefits. ${ }^{2}$ For children with congenital heart disease, parents' knowledge about their child's heart disease, treatment, and prevention of complications may likewise promote a better health related behaviour in their child by increasing the understanding of the cardiac problem, improving compliance with treatment, and avoiding risk taking behaviour. In the past decade, significant advances in transcatheter and surgical management of paediatric cardiac patients have been made. Nonetheless, several recent studies have shown that understanding of illness by children, adolescents, and adults with congenital heart disease remains unsatisfactory. ${ }^{3-13}$ The paediatric cardiac patients may have an entirely wrong concept of their disease, ${ }^{7-10}$ while the majority of adult patients have a poor understanding of symptoms suggestive of cardiac deterioration, risk factors of endocarditis, the impact of smoking and alcohol on heart disease, and the hereditary nature of their cardiac conditions. ${ }^{11-13}$ Given the important role of parents in imparting knowledge of chronic illness to their child, the disappointing findings from previous studies may perhaps reflect inadequacies of parental knowledge.
Previous studies on the knowledge of parents of children with congenital heart disease are limited. ${ }^{3-6}$ Furthermore, only certain aspects have been interrogated. ${ }^{3-6}$ In addition, the relatively small number of parents being recruited limits the power of the study to identify important determinants of parental knowledge. In this study, we therefore assessed the parents' understanding of their child's congenital heart disease in three domains: firstly, the nature of heart disease and its treatment; secondly, the impact of heart disease on exercise capacity; and thirdly, infective endocarditis and its prevention. We further determined, in the light of the findings, significant determinants of parental knowledge in the various domains.

\section{METHODS}

\section{Patients}

In this cross sectional questionnaire survey, parents who were accompanying their child to the outpatient clinic of a tertiary cardiac centre were recruited over a three month period. To enable a more realistic appraisal of parental knowledge, only those who had a child with relatively simple structural heart lesions were included. These cardiac defects were atrial septal defect, ventricular septal defect, atrioventricular septal defect, patent ductus arteriosus, pulmonary stenosis, aortic stenosis, tetralogy of Fallot, and transposition of the great arteries. All parents gave verbal informed 
consent. Parents of children with complex cyanotic heart disease and those with children with a new diagnosis of heart disease were excluded.

\section{Questionnaire}

Demographic data including age, educational level, occupation, and marital status of the parents were obtained during the interview. Their occupations were classified according to the International Standard Classification of Occupations, ${ }^{14}$ with slight modifications, into six categories: professionals, administrators and managers, skilled workers, service workers, unskilled workers, and unemployed. From the medical records, the following data were collected: age and sex of the patient, cardiac diagnosis, associated non-cardiac diseases, family history of congenital heart disease, previous cardiac operations or therapeutic cardiac catheterisations, current medications, and history of infective endocarditis.

The parental knowledge was assessed under three domains: the nature of heart disease and its treatment; the impact of heart lesion on exercise capacity; and infective endocarditis and its prevention. Table 1 summarises the items in each of these three domains. These were based in part on the questionnaire previously used by Moons and colleagues. ${ }^{13}$ A diagram of the normal heart showing the four cardiac chambers and normal connection of the great arteries was shown to parents, who were then asked to draw or indicate the heart defect(s) on the diagram. Answers to each of the topics in the three domains, except for those regarding risk factors predisposing to infective endocarditis, were then determined by paediatric cardiologists to be either correct, incomplete, or incorrect. Answers regarding risk factors predisposing to endocarditis were dichotomised as either correct or incorrect.

A pilot study was carried out with 20 parents to ensure that the questions were easily understood. The questionnaire was administered by one of the three interviewers (DKLC, SMYW, and YPC) during a face to face interview with parents in the outpatient clinic, either before or after their child had been seen by the paediatric cardiologist or resident. All of the questions were presented in a standardised manner, with further clarification if necessary.

\section{Statistical analysis}

Data are expressed as percentages and 95\% confidence intervals. Univariate analysis to assess for associations

Table 1 Items of parental knowledge in the three domains

Domain
Nature of the disease and its treatment
Name of heart disease
Location of heart disease diagrammatically
Aetiology of congenital heart disease
Hereditary nature of heart disease
Symptoms attributable to heart disease
Treatment of heart disease
Surgery
Transcatheter intervention
Medication (function and side effects)
Impact of heart disease on exercise capacity
Exercise prescription and necessity for exercise restriction
Infective endocarditis and its prevention
Awareness of the term "infective endocarditis"
Symptoms of endocarditis
Risk factors of endocarditis
Dental abscess
Contaminated needles
Skin infection
Poor nail and skin care
Body piercing and tattooing

between demographic and clinical variables with selected items of knowledge was performed with the Mann-Whitney $\mathrm{U}$ test, Fisher's exact test, or the $\chi^{2}$ test where appropriate. Multivariate analysis by logistic regression was used to identify significant determinants of selected items of knowledge. The dependent knowledge variable was dichotomised as a correct or incorrect answer. Incorrect answers were deemed as incomplete, incorrect, and don't know answers. A probability value of $p<0.05$ was considered significant. All statistical analyses were done with SPSS version 10.0 (SPSS Inc, Chicago, Illinois, USA)

\section{RESULTS}

\section{Demographic data}

Table 2 summarises demographic data of the parents and patients. One hundred and fifty six parents (112 were mothers and 44 fathers) of 156 patients (78 boys) were interviewed. The median age of mothers was 38 years (range 26-52 years) and that of fathers was 41 years (range 28-65 years). The majority of parents (83\% of fathers and $82 \%$ of mothers) had at least completed high school education. Most of the fathers were skilled workers $(42.9 \%)$ and most of the mothers were housewives (56.4\%) (table 2 ). The median age of patients at the time of study was six years (range one month to 21 years). Of the 156 patients, 101 (64.7\%) had

Table 2 Demographic and clinical variables

\begin{tabular}{|c|c|c|}
\hline \multirow{2}{*}{$\begin{array}{l}\text { Parents/patients } \\
\text { Parents }\end{array}$} & \multicolumn{2}{|l|}{ Frequency } \\
\hline & Father & Mother \\
\hline Responder & $44(28.2 \%)$ & $112(71.8 \%)$ \\
\hline \multicolumn{3}{|l|}{ Occupational status } \\
\hline Professionals & $17(10.9 \%)$ & $14(9.0 \%)$ \\
\hline Administrators and managers & $25(16.0 \%)$ & $6(3.8 \%)$ \\
\hline Skilled workers & $67(42.9 \%)$ & $30(19.2 \%)$ \\
\hline Service workers & $15(9.6 \%)$ & $10(6.4 \%)$ \\
\hline Unskilled workers & $22(14.1 \%)$ & $7(4.5 \%)$ \\
\hline Unemployed & $10(6.4 \%)$ & $88(56.4 \%)$ \\
\hline \multicolumn{3}{|l|}{ Educational level } \\
\hline Primary or below & 27 (17.3\%) & $28(17.9 \%)$ \\
\hline Secondary & $109(69.9 \%)$ & $113(72.4 \%)$ \\
\hline Tertiary non-degree & $3(1.9 \%)$ & $6(3.8 \%)$ \\
\hline Tertiary degree & $17(10.9 \%)$ & $9(5.8 \%)$ \\
\hline \multicolumn{3}{|l|}{ Patients } \\
\hline \multicolumn{3}{|l|}{ Sex } \\
\hline Male & $78(50.0 \%)$ & \\
\hline Female & $78(50.0 \%)$ & \\
\hline \multicolumn{3}{|l|}{ Diagnosis } \\
\hline VSD & $52(33.3 \%)$ & \\
\hline TOF & $35(22.4 \%)$ & \\
\hline ASD & $26(16.7 \%)$ & \\
\hline PDA & $14(9.0 \%)$ & \\
\hline PS & $13(8.3 \%)$ & \\
\hline TGA & $8(5.1 \%)$ & \\
\hline AVSD & $7(4.5 \%)$ & \\
\hline AS & $1(0.6 \%)$ & \\
\hline \multicolumn{3}{|l|}{ Current medication } \\
\hline Yes & $25(16.0 \%)$ & \\
\hline No & $131(84.0 \%)$ & \\
\hline \multicolumn{3}{|c|}{ Previous operation or interventional catheterisation } \\
\hline Yes & $101(64.7 \%)$ & \\
\hline No & $55(35.3 \%)$ & \\
\hline \multicolumn{3}{|l|}{ Associated diseases } \\
\hline Yes & $36(23.1 \%)$ & \\
\hline No & $120(76.9 \%)$ & \\
\hline \multicolumn{3}{|c|}{ Family history of congenital heart disease } \\
\hline Yes & $24(15.4 \%)$ & \\
\hline No & $132(84.6 \%)$ & \\
\hline \multicolumn{3}{|l|}{ History of infective endocarditis } \\
\hline Yes & $0(0.0 \%)$ & \\
\hline No & $156(100.0 \%)$ & \\
\hline
\end{tabular}

AS, aortic stenosis; $A S D$, atrial septal defect; $A V S D$, atrioventricular septal defect; PDA, patent ductus arteriosus; PS, pulmonary stenosis; TGA, transposition of great arteries; TOF, tetralogy of Fallot; VSD, ventricular septal defect. 
undergone previous corrective operations or therapeutic cardiac catheterisations and $25(16 \%)$ were taking cardiac medications. A positive family history of congenital heart disease was present in 24 (15.4\%) patients.

\section{Parental knowledge in various domains}

\section{Nature of the heart disease and its treatment}

While $59 \%$ of parents correctly named their child's congenital heart disease, only $28.8 \%$ correctly indicated the heart lesion(s) on the diagram (table 3 ). Although most parents could describe the presence of a hole inside the heart, they could not specify by name or on the diagram whether it was an atrial, ventricular, or atrioventricular type of defect. On the other hand, while almost all parents could name tetralogy of Fallot correctly, locating all the structural lesions on the diagram was difficult for them. Nonetheless, parents were very knowledgeable about their child's past interventions, including surgical and transcatheter ones. More than $80 \%$ of parents were aware of the indications and aims of these interventions. About half of the parents were aware of the hereditary nature and possible aetiologies of congenital heart disease and symptoms attributable to the disease. Disappointingly, of the 56 parents whose child was taking cardiac medications at the time of study, only $25(44.6 \%)$ and $4(7.1 \%)$ knew correctly the functions and important side effects of the medications, respectively.

\section{Impact of heart disease on exercise capacity}

Fifty nine per cent of parents answered correctly on the necessity for exercise restriction appropriate for their child's heart condition (table 3 ). The majority of the remaining parents, however, tended to impose excessive exercise restriction.

\section{Infective endocarditis and its prevention}

None of the patients in this cohort had documented episodes of infective endocarditis (table 3). Only $26.9 \%$ (42 of 156) of all parents had heard of the term infective endocarditis. Despite this, slightly more than half $(52.4 \%)$ of the parents knew that antibiotics had to be taken before dental procedures, although they may not be aware of the underlying reason for doing so.
Of the 42 parents who had heard of infective endocarditis, only $12(28.6 \%)$ correctly stated the symptoms of endocarditis (table 3). Dental abscess, the most well known risk factor of infective endocarditis, was correctly identified by only 21 parents $(50 \%)$. Contaminated needles, body piercing and tattooing, skin infection, and poor skin and nail care were identified correctly as risk factors of endocarditis by 15 $(35.7 \%), 15(35.7 \%), 13(31 \%)$, and $11(26.2 \%)$ parents, respectively.

\section{Determinants of parental knowledge}

Univariate analysis showed that cyanotic heart diseases, including tetralogy of Fallot and transposition of the great arteries, were named correctly more often than acyanotic ones $(90.7 \% \vee 46.9 \%, \mathrm{p}<0.001)$. Professionals, administrators, and skilled workers were more likely to name the heart lesions correctly than service workers, unskilled workers, or unemployed parents $(67.9 \% v 38.3 \%, p=0.001$ for fathers, and $76 \%$ v $51.4 \%, \mathrm{p}=0.004$ for mothers). Parents with an educational attainment of at least high school level were more likely to name the heart lesions correctly than those with primary school level or lower $(80 \%$ v 55.9\%, $p=0.041$ for fathers, and $64.5 \% v 46.2 \%, p=0.046$ for mothers). Likewise, the ability to indicate correctly the heart defect on the diagram was related to cardiac diagnosis $(p=0.021)$, occupation $(p<0.01)$, and educational level $(\mathrm{p}<0.05)$ of both parents. Across the cardiac diagnostic categories, $68 \%, 63 \%, 43 \%, 39 \%$ of parents correctly indicated abnormalities of tetralogy of Fallot, transposition of the great arteries, valvar stenosis, and left to right shunts on the diagram, respectively $(\mathrm{p}=0.021)$.

Regarding descriptions of cardiac symptoms, parents of children with cyanotic heart disease, compared with those with children who had acyanotic heart disease ( $86 \%$ v 38.1\%, $\mathrm{p}<0.001)$, parents of patients who had previous interventions $(60.4 \% \vee 34.5 \%, p=0.002)$, and fathers who were professionals, administrators, or skilled workers $(56.9 \% v$ $38.3 \%, p=0.033$ ) were more likely to be correct. On the other hand, parents whose children were older (median age $7.2 v 4.4$ years, $\mathrm{p}=0.045$ ) were more likely to give correct answers to the question on exercise prescription.

Awareness of infective endocarditis was related to age of the patient, frequency of follow up, and the father's

Table 3 Parental knowledge in the various domains

\begin{tabular}{|c|c|c|c|c|}
\hline Items & Correct (\%) $(95 \% \mathrm{Cl})$ & Incomplete (\%) $(95 \% \mathrm{Cl})$ & Incorrect (\%) $(95 \% \mathrm{CI})$ & Don't know (\%) $(95 \% \mathrm{Cl})$ \\
\hline \multicolumn{5}{|l|}{ Nature of the heart disease and its treatment } \\
\hline Name & $59.0(51.3$ to 66.7$)$ & 33.3 ( 25.9 to 40.7$)$ & $3.8(0.8$ to 6.8$)$ & $3.8(0.8$ to 6.8$)$ \\
\hline Diagrammatic location & 28.8 (21.7 to 35.9$)$ & 18.6 (12.5 to 24.7$)$ & 22.4 (15.9 to 28.9$)$ & 30.1 (22.9 to 37.3$)$ \\
\hline Aetiology & 47.4 (39.6 to 55.2$)$ & $1.3(0.0$ to 3.1$)$ & $4.5(1.2$ to 7.8$)$ & $46.8(39.0$ to 54.6$)$ \\
\hline Hereditary nature & $64.1(56.6$ to 71.6$)$ & $1.3(0.0$ to 3.1$)$ & $8.3(4.0$ to 12.6$)$ & $26.3(19.4$ to 33.7$)$ \\
\hline Symptoms & $51.3(43.5$ to 59.1$)$ & $10.3(5.5$ to 15.1$)$ & $28.8(21.7$ to 35.9$)$ & $9.6(5.0$ to 14.2$)$ \\
\hline Treatments offered & $96.8(94.0$ to 99.6$)$ & $3.2(0.4$ to 6.0$)$ & $0.0(0.0$ to 0.0$)$ & $0.0(0.0$ to 0.0$)$ \\
\hline \multicolumn{5}{|l|}{ Objectives of treatments } \\
\hline Surgery $(n=97)$ & 82.5 (77.5 to 87.5$)$ & $12.4(5.8$ to 19.0$)$ & $2.1(0.0$ to 5.0$)$ & $3.1(0.0$ to 6.5$)$ \\
\hline Interventional catheterisation ( $n=32$ ) & $90.6(80.5$ to 100.0$)$ & $0.0(0.0$ to 0.0$)$ & $0.0(0.0$ to 0.0$)$ & $9.4(0.0$ to 19.5$)$ \\
\hline Medications $(n=56)$ & 44.6 (31.6 to 57.6$)$ & $19.6(9.2$ to 30.0$)$ & 16.1 (6.5 to 25.7$)$ & $19.6(9.2$ to 30.0$)$ \\
\hline $\begin{array}{l}\text { Side effects of medications }(n=56) \\
\text { Impact of heart disease on exercise capacity }\end{array}$ & $7.1(0.4$ to 13.8$)$ & $8.9(1.4$ to 16.4$)$ & $19.6(9.2$ to 30.0$)$ & $64.3(51.8$ to 76.8$)$ \\
\hline $\begin{array}{l}\text { Exercise prescription and need for exercise } \\
\text { restriction }\end{array}$ & $59.0(51.3$ to 66.7$)$ & $1.3(0.0$ to 3.1$)$ & 35.9 (28.4 to 43.4$)$ & $3.8(0.8$ to 6.8$)$ \\
\hline \multicolumn{5}{|l|}{ Infective endocarditis and its prevention } \\
\hline Awareness of infective endocarditis & 26.9 (19.9 to 33.9$)$ & $0.0(0.0$ to 0.0$)$ & $0.0(0.0$ to 0.0$)$ & $73.1(66.1$ to 80.1$)$ \\
\hline Symptoms of endocarditis ( $n=42$ ) & 28.6 (14.9 to 42.3$)$ & 4.8 (0.0 to 11.3$)$ & $0.0(0.0$ to 0.0$)$ & 66.7 (52.4 to 81.0$)$ \\
\hline \multicolumn{5}{|l|}{ Risk factors of endocarditis ( $n=42$ ) } \\
\hline Dental abscess & 50.0 (34.9 to 65.1$)$ & & 11.9 (2.1 to 21.7$)$ & 38.1 (23.4 to 52.8$)$ \\
\hline Contaminated needles & 35.7 (21.2 to 50.2$)$ & & 14.3 (3.7 to 24.9 ) & 50.0 (34.9 to 65.1$)$ \\
\hline Skin infection & $31.0(17.0$ to 45.0$)$ & & $21.4(9.0$ to 33.8$)$ & 47.6 (32.5 to 62.7$)$ \\
\hline Poor nail and skin care & $26.2(12.9$ to 39.5$)$ & & $26.2(12.9$ to 39.5$)$ & $47.6(32.5$ to 62.7$)$ \\
\hline Body piercing and tattooing & $35.7(21.2$ to 50.2$)$ & & $16.7(4.8$ to 28.6$)$ & $47.6(32.5$ to 62.7$)$ \\
\hline
\end{tabular}


occupation and educational level. Parents who were aware of infective endocarditis had older children (median age $8.0 \mathrm{v}$ 5.3 years, $p=0.04$ ), less frequent follow up ( $8 v 6$ monthly, $\mathrm{p}=0.047)$, and higher education attainment $(30.2 \% v$ $11.1 \%, p=0.042$ ) and more likely to be professionals, administrators, or skilled workers $(32.1 \% v 14.9 \%, \mathrm{p}=0.026)$.

Table 4 summarises the results of logistic regression. The findings showed that cardiac diagnosis and occupations of parents were the main determinants of parents' knowledge of the nature of their child's heart disease. Cyanotic heart lesions were more likely than acyanotic heart lesions to be named and indicated on the diagram correctly. Furthermore, symptoms attributable to cyanotic lesions were more likely to be described correctly by parents. Professionals, administrators, and skilled workers were likewise more likely to give correct answers when asked to name, indicate on a diagram, and provide possible causes of the congenital heart disease. No significant determinants of knowledge regarding the impact of heart disease on exercise capacity and infective endocarditis were identified by logistic regression.

\section{DISCUSSION}

In this study, we have assessed parents' understanding of their child's congenital heart disease in different domains, which differs from most of the previous studies that focused on particular aspects. ${ }^{3-6}$ Despite recent advances in medical and surgical management of paediatric cardiac patients, the findings of the present study suggest that parents have important knowledge gaps. While the majority of parents could name the cardiac lesion, either in part or completely, and were knowledgeable concerning previous surgical or transcatheter interventions, their knowledge of the aetiology and symptoms of congenital heart disease were limited. Furthermore, only slightly more than half were aware of the impact of their child's heart disease on exercise capacity. Disappointingly, their knowledge about infective endocarditis and side effects of cardiac medications appear to be quite deficient.

In the present study $59 \%$ of parents named their child's heart defect correctly, which is comparable with the 27-98\% reported previously. ${ }^{4-6}$ The wide percentage range in the literature is perhaps not unexpected when determinants of parental knowledge in this domain are considered. Kaden and colleagues ${ }^{6}$ reported that parental understanding of heart defects correlates with parental occupation and educational level. ${ }^{6}$ Likewise, we identified these as significant determinants in the present cohort. Additionally, the cardiac diagnosis was found to be a significant determinant. Indeed, Moons and colleagues ${ }^{13}$ have shown that in adult patients with congenital heart disease, correct location of the heart defect is determined by the primary cardiac diagnosis. Interestingly, we found that tetralogy of Fallot and transposition of the great arteries were more likely to be named correctly, probably because the name of the diagnosis itself is composite and specific, in contrast to the non-specific description of "a hole within the heart" for the various types of septal defects.

As alluded to earlier, parents' understanding of the side effects of medications was disappointingly poor in our cohort. This is perhaps related to emphasis being placed on the potential beneficial effect of the medications and the importance of compliance on the part of the medical staff, and to the relative lack of emphasis on the potential side effects, especially when parents did not take the initiative to ask.

There have been no previous studies on parental knowledge of exercise prescription for children with congenital heart disease. Recently, Swan and colleagues ${ }^{15}$ reported that parents commonly have misconceptions about exercise prescription for adult patients with congenital heart disease. Parents of children with heart disease had similar misconceptions in this regard. It is perhaps not surprising that parents of older children had a better understanding, as questions regarding the need for exercise restriction are usually asked when their children enter primary school.

The poor awareness of infective endocarditis is not unique to this cohort. Previous studies have reported that only $14-63 \%$ of parents know about infective endocarditis. ${ }^{3-5}$ It is possible that when parents were counselled on prevention against infective endocarditis, lay terms such as "infection" or "inflammation of heart tissue" were used and that the parents may not be fully aware of the significance of this clinical entity. While parents of children younger than 5 years were reported to know less about infective endocarditis, ${ }^{4}$ the findings were not confirmed in a subsequent study. ${ }^{5}$ In the present study, although parents of older children were found to be more knowledgeable on this issue by univariate analysis, this factor becomes insignificant after adjustment for other demographic and clinical variables.

Some limitations of this study may deserve comment. Firstly, as no standard instrument for evaluating parental knowledge of congenital heart disease is available, our questionnaire was based in part on the one reported recently by Moon and colleagues. ${ }^{13}$ Undoubtedly, formal assessment of the psychometric properties, internal consistency, reliability, and validity of these questionnaires is ideal and should be the target in future large scale surveys. Nevertheless, semistructured questionnaires, used previously in some studies, ${ }^{5}{ }^{13}$ have similarly yielded important data in the assessment of patient and parental knowledge on congenital heart disease. Secondly, as some of the parents were

Table 4 Logistic regression analysis of determinants of parental knowledge

\begin{tabular}{|c|c|c|c|c|c|}
\hline Dependent variable & Covariate & OR & $95 \% \mathrm{Cl}$ & p Value & $R^{2}$ \\
\hline \multicolumn{6}{|c|}{ Name of heart disease } \\
\hline & Left to right shunt $v$ cyanotic heart & 0.032 & 0.007 to 0.137 & $<0.001$ & 0.460 \\
\hline & Valvar stenosis $v$ cyanotic heart & 0.114 & 0.019 to 0.700 & 0.019 & \\
\hline & Skilled workers $v$ unemployed (mothers) & 3.79 & 1.08 to 13.2 & 0.037 & \\
\hline & Professional or administrative workers $v$ unemployed (fathers) & 19.7 & 1.28 to 303 & 0.033 & \\
\hline & Skilled workers $v$ unemployed (fathers) & 24.1 & 1.88 to 309 & 0.014 & \\
\hline \multicolumn{6}{|c|}{ Location of heart defect(s) on diagram } \\
\hline & Left to right shunt $v$ cyanotic heart lesion & 0.318 & 0.126 to 0.805 & 0.016 & 0.301 \\
\hline & Professional workers $v$ unemployed (mothers) & 8.19 & 1.54 to 43.4 & 0.014 & \\
\hline \multicolumn{6}{|c|}{ Aetiologies of heart disease } \\
\hline & Professional or administrative workers $v$ unemployed (mothers) & 30.8 & 3.02 to 313 & 0.004 & 0.413 \\
\hline & Skilled workers $v$ unemployed (mothers) & 4.69 & 1.63 to 13.6 & 0.004 & \\
\hline & Left to right shunt $v$ cyanotic heart lesion & 0.096 & 0.033 to 0.281 & $<0.001$ & 0.347 \\
\hline \multicolumn{6}{|c|}{ Symptoms of heart disease } \\
\hline & Valvar stenosis $v$ cyanotic heart lesion & 0.038 & 0.008 to 0.184 & $<0.001$ & 0.347 \\
\hline
\end{tabular}


interviewed after the cardiac consultation, a possible confounding influence relating to knowledge reinforcement cannot be completely eliminated. Nonetheless, as the attending doctor is not aware of the interview that follows, it seems unlikely that the messages given during consultation would differ from usual. Thirdly, it is important to note that the findings of this study reflect parental knowledge on relatively simple congenital heart lesions.

Despite these potential limitations, the findings from this and other studies have important implications. The need for education of these parents, through structured and repetitive educational activities, about aspects of congenital heart disease and the use of illustrations cannot be overemphasised. Greater attention should be given to the at risk groups.

In conclusion, from this cross sectional study, we have identified important knowledge gaps in parents of children with various types of simple congenital heart disease. The current education programme needs to be refined to achieve better parental understanding of their child's heart disease, with the ultimate aim of enabling parents to impart accurately their knowledge to their children.

\section{Authors' affiliations}

D K L Cheuk, S M Y Wong, Y P Choi, A K T Chau, Y F Cheung, Division of Paediatric Cardiology, Department of Paediatrics and Adolescent Medicine, Grantham Hospital, The University of Hong Kong, Hong Kong, China

\section{REFERENCES}

1 Gochman D. Handbook of health behaviour research, vol 1. New York: Plenum Press, 1997.

2 Harm T. Patient education in Estonia. Patient Educ Couns 2001;44:75-8.

3 Caldwell RL, Hurwitz RA, Girod DA. Subacute bacterial endocarditis in children: current status. Am J Dis Child 1971;122:312-5.

4 Sholler GF, Celermajer JM. Prophylaxis of bacterial endocarditis: awareness of need. Med J Aust 1984;140:650-2.

5 Cetta F, Bell TJ, Podlecki DD, et al. Parental knowledge of bacterial endocarditis prophylaxis. Pediatr Cardiol 1993;14:220-2.

6 Kaden GG, McCarter RJ, Johnson SF, et al. Physician-patient communication: understanding congenital heart disease. Am J Dis Child 1985;139:995-9.

7 Cetta F, Graham LC, Lichtenberg RC, et al. Piercing and tattooing in patients with congenital heart disease: patient and physician perspective. J Adolesc Health 1999; 24: 160-2.

8 Cetta F, Podlecki DC, Bell TJ. Adolescent knowledge of bacterial endocarditis prophylaxis. J Adolesc Health 1993;14:540-2.

9 Veldtman GR, Matley SL, Kendall L, et al. Illness understanding in children and adolescents with heart disease. Heart 2000;84:395-7.

10 Vessey JA, O'Sullivan P. A study of children's concepts of their internal bodies: a comparison of children with and without congenital heart disease. J Pediatr Nurs 2000; 15:292-8.

11 Cetta F, Warnes CA. Adults with congenital heart disease: patient knowledge of endocarditis prophylaxis. Mayo Clin Proc 1995;70:50-4.

12 Kantoch MJ, Collins-Nakai RL, Medwid SM, et al. Adult patients' knowledge about their congenital heart disease. Can J Cardiol 1997; 13:641-5.

13 Moons $\mathbf{P}$, Volder ED, Budts W, et al. What do adult patients with congenital heart disease know about their disease, treatment, and prevention of complications? A call for structured patient education. Heart 2001;86:74-80.

14 Anon. Hong Kong annual digest of statistics. Hong Kong: Hong Kong Special Administrative Region, Hong Kong Census and Statistics Department, 2001:23.

15 Swan L, Hillis WS. Exercise prescription in adults with congenital heart disease: a long way to go. Heart 2000;83:685-7.

\section{IMAGES IN CARDIOLOGY}

\section{5 -Flurouracil induced coronary artery vasospasm}

A 32 year old woman was treated with 5-flurouracil (5-FU) infusion for carcinoma of the colon. During the infusion she developed severe central chest pain and hence it was stopped. An ECG revealed 1-2 mm global ST segment elevation (upper panel). Her cardiac risk factors include family history of ischaemic heart disease. Her random cholesterol was $3.6 \mathrm{mmol} / \mathrm{l}$. She was transferred to a tertiary centre for further management. After transfer her chest pain had completely resolved and the repeat ECG was normal (lower panel). On inquiry she admitted to having transient chest pain three weeks before this, during a previous 5-FU infusion which resolved as soon as the infusion was stopped. No ECG was done on that occasion. Since there was clinical and ECG resolution coronary angiography was deferred. Her troponin $\mathrm{T}$ value was normal. Hence she was reassured and discharged. Six weeks later coronary angiography demonstrated normal coronaries.

Cardiotoxicity is an uncommon adverse effect of 5-FU treatment. The underlying mechanisms of cardiotoxicity are not fully understood, although coronary vasospasm may be responsible. Patients may present with angina, myocardial infarction, arrhythmias and/or even sudden death. When the drug is readministered, there is a high risk of recurrence and therefore should be avoided.
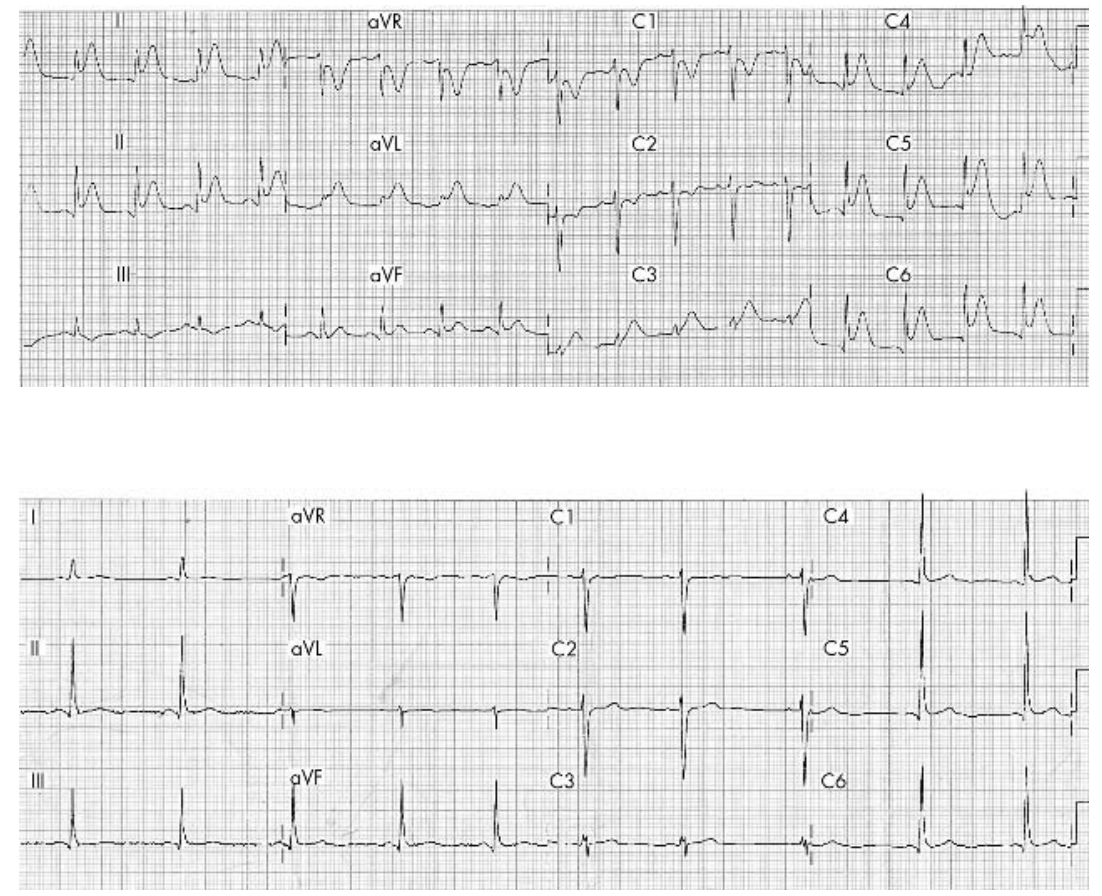

V Suresh

A Khavandi

H Hancock

sureshpriya2000@yahoo.com 